\section{НИКОНОВА Татьяна Викторовна а, ГУСАРОВА Валерия Юрьевна ${ }^{6}$, ПЕРЕЖОГИНА Ольга Николаевна ${ }^{\text {B }}$}

УДК 379.85

DOI: 10.22412/1995-0411-2017-11-3-51-58

\author{
Поволжская государственная академия физической культуры, \\ спорта и туризма (Казань, Респ. Татарстан, РФ); \\ а кандидат экономических наук, доцент; e-mail: viktta@mail.ru; \\ ${ }^{6}$ кандидат экономических наук, ст. преподаватель; e-mail: vgusarova@mail.ru; \\ ${ }^{8}$ кандидат экономических наук, $\mathrm{cm}$. преподаватель; \\ e-mail: perezhogina-on@yandex.ru
}

В последние несколько лет развитие приключенческого туризма, как разновидности активного туризма, инициативами туристических фирм стало иметь более заметный характер. Adventuretourism (приключенческий туризм) отличается оригинальностью и необычным разнообразием туров, это могут быть различные экзотические путешествия, с использованием экстремальных видов спорта, определённых средств перемещения, в то же время, подвергаясь риску и опасности жизни. В этой связи в статье выделены критериальные отличия приключенческого туризма от иных активных видов путешествий. Среди основных причин популярности приключенческого туризма авторами статьи признается: популяризация в обществе здорового образа жизни, престиж активности на отдыхе, стремление современного туриста к новым впечатлениям и выплеску эмоций, возможность самореализации, повышения авторитета, а также продвижения в социуме через приключенческий туризм, что достигается в том числе через соисети. Учитывая растущую популярность приключенческого туризма в мире, авторами статьи проанализированы факторы конкурентоспособности России для развития приключенческого туризма. Выявлено, что сильными сторонами являются инфраструктура железнодорожного транспорта, а также высокий уровень здравоохранения и гигиены. В статье признается, что на настоящий момент развитие приключенческого туризма в России сдерживается целым рядом отрицательных фракторов, требующих устранения. $K$ их числу отнесены: отсутствие комплексного взгляда на географию России с позиций выделения приключенческих территорий, неудовлетворительный уровень туристской инфраструктуры приключений, слабый ассортимент и невысокое качество предлагаемых сервисных услуг приключенческого туризма, слабая профессиональная подготовленность кадров.

Ключевые слова: приключенческий туризм, активный туризм, туристская инфраструктура, рейтинг глобальной конкурентоспособности, услуги приключенческого туризма.

Введение. До недавнего времени приключенческий туризм в России был недостаточно популярен, он продвигался преимущественно усилиями увлечённых изучением территории страны и собственных возможностей инициаторов, объединённых туристических клубов и сообществ.

В последние несколько лет развитие приключенческого туризма, как разновидности активного туризма, инициативами туристических фирм стало иметь более заметный характер. В этом способствует как ответственная работа квали- фицированных специалистов, постоянно проводящих мониторинг маршрутов и обеспечивающих во время проведения путешествий безопасность, так и наличие у туркомпаний специального снаряжения, оборудования и средств связи, позволяющих приобщиться к приключенческому отдыху лицам, не обладающим подготовкой и специальными знаниями в области самостоятельных путешествий.

Разработка приключенческого тура довольно сложный и трудоёмкий процесс, чтобы пользоваться значительным успехом и привлекать потребителей, необхо- 
димо создать интересный и необычный туристский продукт.

\section{Отличительные особенности и роль приключенческого туризма}

Adventuretourism (приключенческий туризм) отличается оригинальностью и необычным разнообразием туров, это могут быть различные экзотические путешествия, с использованием экстремальных видов спорта, определённых средств перемещения, в то же время, подвергаясь риску и опасности жизни [3].

К таким приключениям нужно быть не только физически подготовленным, но и морально. Рассматриваемый вид туризма целиком и полностью схож со спортивным туризмом, так как здесь применены активные виды передвижения людей, но отличается тем, что мероприятия значительно подготовлены и комфортабельны [8, 12]. Маршруты приключенческого туризма более безопасны, но учитывается тот факт, что могут быть определённо дороже [2, с. 23].

В табл. 1 приведены основные критериальные отличия приключенческого туризма от иных активных видов путешествий.

Таблица 1 - Отличия приключенческого туризма

Table 1 -Differences of adventure tourism

\begin{tabular}{|l|l|}
\hline \multicolumn{1}{|c|}{ Критерий } & \multicolumn{1}{c|}{ Описание } \\
\hline Цель & Получение максимума впечатлений от выезда \\
\hline Содержание программ туризма & $\begin{array}{l}\text { Достаточно насыщенные программы пребывания, независи- } \\
\text { мо от выбранной для выезда страны }\end{array}$ \\
\hline $\begin{array}{l}\text { Условия передвижения и прожива- } \\
\text { ния }\end{array}$ & $\begin{array}{l}\text { Предпочтение отдаётся наиболее комфортным условиям пе- } \\
\text { редвижения и проживания }\end{array}$ \\
\hline Продолжительность программ & $\begin{array}{l}\text { Программы, как правило короткие, в среднем составляют они } \\
2-4 \text { дня, часто среди них встречаются туры выходного дня, а } \\
\text { также праздничные специализированные программы }\end{array}$ \\
\hline Средний возраст путешествующих & $\begin{array}{l}\text { Программы ориентированы на туристов возрастом от 18 и до } \\
\text { З5 лет. Реже туры адресованы семьям с детьми и лицам стар- } \\
\text { ших возрастов }\end{array}$ \\
\hline Средний размер туристских групп & $\begin{array}{l}\text { Главным образом индивидуальные туры (в составе малочис- } \\
\text { ленных групп) }\end{array}$ \\
\hline $\begin{array}{l}\text { Наличие особых требований к орга- } \\
\text { низации приключенческого тура }\end{array}$ & $\begin{array}{l}\text { Необходимость чёткой проработки условий техники безопас- } \\
\text { ност. Чем сложнее туристский приключенческий маршрут, } \\
\text { темачительнее требования к его организации и подготов- } \\
\text { ленности участников }\end{array}$ \\
\hline $\begin{array}{l}\text { Наличие особых требований к путе- } \\
\text { шествующим }\end{array}$ & $\begin{array}{l}\text { Приключенческие туры доступны людям с нормальными по- } \\
\text { казалями здоровья, но имеются маршруты, требующие опы- } \\
\text { определённым психическим и эмоциональным напряжением }\end{array}$ \\
\hline
\end{tabular}

В приключенческом туризме важно обеспечение оптимального желаемого уровня риска, который максимизирует спрос на приключенческий туризм [13], а также выявление склонности у туристов к жёсткому и мягкому приключенческому туризму на основе анализа интереса путешественников к культурным переживаниям [15].
Но при этом нужно учитывать особенности факторов ценности, влияющих на удовлетворение и поведенческие намерения туристов различных стран. К примеру, японские туристы придают значение в первую очередь эмоциональной ценности и ценности новизны, туристы из Европы исходят из критерия практичности и соизмеряют полученные полезности от тура с 
той суммой средств, что была уплачена за тур [16].

Особенностью приключенческого туризма последних лет является также и тенденция дезинтермедиации, то есть устранение посредника (туроператора или турагента), который традиционно сводит потребителя на исходном рынке с целевым рынком.

Так, изучение рынка приключений Соединённых Штатов Америки, указывает, что $71 \%{ }^{1}$ приключенческих путешествий были организованы исключительно самостоятельно путешественниками.

Говоря о современной роли приключенческого туризма, следует отметить, что он выступает естественной альтернативой туризму «чемоданному».

Во-первых, он способствует насыщению организма путешественников адреналином. Речь идёт именно о физиологических характеристиках явлений. Это происходит вследствие осознанного приобщения путешественников в ситуации с повышенными психо-эмоциональными и физическими нагрузками [5, с. 298].

Во-вторых, приключение олицетворяет у туристов встречу со всем новым и необычным, в этом смысле он способствует психофизиологической разгрузке, выходу за рамки рутины, предлагает модель адаптации в условиях хронического нервно-психического напряжения [6].

В-третьих, приключенческий туризм выполняет яркую познавательную роль, предлагая зачастую труднодоступные памятники, к примеру, «нераскрученные» памятники археологии, истории, культуры и даже промышленные объекты, которые могут быть интересны для приключенческих туристов [7, 14].

\section{Современное состояние рынка приключенческого туризма}

По данным журнала National Geographic, согласно результатам опроса читателей, в тройку лучших направлений для путешественников приключенческо-

1 Глобальный доклад по приключенческому туризму. 2015. URL: http: // cf.cdn.unwto.org/sites/ all/files/pdf/final_1global_report_on_adventure_ tourism.pdf (Дата обращения: 14.06.2017). го туризма в 2016 г. вошли: США (25\%), Марокко (20\%), Непал (20\%). Среди регионов России Алтайский край выделен регионом с лучшими приключенческими турами. В пользу этого региона выступили $25 \%$ опрошенных читателей журнала. На втором месте находится Камчатка $22 \%$, на третьем - Карелия с результатом в $14 \%^{2}$.

Особый спрос на приключенческий туризм предъявляют туристы из развитых стран мира. Так, по данным Ассоциации туроператоров ${ }^{3}$, приключенческий туризм выступает одним из ключевых рынков для туристов в Великобритании, принося в качестве годового дохода около 2 млн фунтов стерлингов.

Рынок приключенческого туризма Канады также набирает серьёзные обороты, демонстрируя ежегодно 20\% прироста. Примечательно, что 26\% турпоездок в мире включает тот или иной элемент приключенческого туризма. А к 2050 г. эта величина составит уже 50\%. Маркетологи признают также высокую маржинальность приключенческого туризма, поскольку в ряде случаев он требует специальной амуниции и снаряжения, которые достаточно дорогостоящи.

Что касается стран-реципиентов, то для многих слаборазвитых стран приключенческий туризм обеспечивает существенный приток доходов.

Имеются страны, специализирующиеся на данном виде активного туризма. Например, Индия и Новая Зеландия отличны тем, что существенная доля иностранных туристов (примерно $40 \%$ от совокупного количества туристов, въезжающих в страну) посещают эти страны именно в поисках приключений, обеспечивая приток валютной выручки.

Рассмотрим причины популярности приключенческого туризма:

1) популяризация в массах здорового образа жизни;

2) престиж активной деятельности;

2 National Geographic Traveler Awards 2016. URL: http://www.nat-geo.ru/ngt-awards-2016/nomination/(дата обращения: 14.06.2017).

3 Ассоциация туроператоров России. Официальный сайт. URL: http://www.atorus.ru (дата обращения: 14.06.2017). 
3) стремление к новым впечатлениям и выплеску эмоций, свойственных приключенческому туризму;

4) возможность самореализации, повышения авторитета, а также продвижения в социуме.

Примечательно, что статистика, опубликованная ЮНВТО и Торговой ассоциацией приключенческого туризма в глобальном докладе по приключенческому туризму, отмечает, что лишь небольшая доля приключенческих туристов (12\%) путешествует в одиночку, 21\% путешествуют с друзьями, 37\% путешествуют с супругом или партнёром, а 30\% - с семьями, включая детей. ${ }^{4}$

У приключенческого туризма нет определённых стандартов, не даётся точного определения, также не имеется чёткой формулы создания приключенческой программы тура.

\section{Факторы развития приключенческого туризма в РФ}

В России туристические компании обладают собственным мнением по поводу того, что же представляет собой приключенческий туризм в общем. Многие из турагентов определяют приключенческий тур как многодневные путешествия, это могут быть различные маршруты, и также называют экстремальным туризмом и советуют всем любителям адреналина отправиться в такое путешествие.

Туроператоры к данному вопросу подходят осторожно, понимают, насколько серьёзна тема безопасности, и это может коснуться, в первую очередь, репутации туристической фирмы [11].

Чем проблематичнее утверждённый маршрут, тем бескомпромисснее должны соответствовать запросы к степени подготовки участников. Участие в приключенческом туре сопровождается определённым психическим и эмоциональным напряжением. Некие ситуации, кроме удоволь-

4 Глобальный доклад по приключенческому туризму. 2015. URL: http://cf.cdn.unwto.org/sites/ all/files/pdf/final_1global_report_on_adventure_ tourism.pdf (дата обращения: 14.06.2017).

National Geographic Traveler Awards 2016. URL: http://www.nat-geo.ru/ngt-awards-2016/nomination/ (дата обращения: 14.06.2017). ствия, могут привести к перенапряжению и срыву высшей нервной деятельности.

На сегодняшний день туроператоры практически не занимаются разработкой новых приключенческих маршрутов из-за их низкой рентабельности и популярности. Также нужно заметить, что современные туристы осведомлены о хорошем сервисе и ждут эксклюзива в туристских программах, поэтому, чтобы предложить конкурентоспособный продукт на рынке туристских услуг, фирме необходимо предлагать не стандартный, а отличающийся от конкурентов туристический продукт.

Особую роль в развитии приключенческого туризма играет инфраструктура: дороги, аэропорты, жилые помещения и туристские тропы.

С высоким рейтингом в категории «Инфраструктура» в 2015 г. были представлены страны: Австралия, Германия, Исландия, Микронезия, Намибия, Новая Зеландия, Перу, Южная Африка, Швейцария, Турция.

В Российской Федерации индустрия туризма ориентирована преимущественно на выезды за пределы страны. Огромное количество действующих туристических фирм занимаются отправлением туристов за рубеж, и всего лишь малая их часть старается привлечь граждан в Россию интересным туристским продуктом. Приключенческий туризм развивается довольно слабыми темпами на российском рынке туристских услуг [4]. Наша страна обладает великим потенциалом для создания туристского продукта и развития выбранного вида туризма.

Согласно опросам, более половины россиян, выезжавших в зарубежные туры, не владеют информацией о наличии возможностей аналогичного отдыха на родине. Речь идёт не только о уникальности природы или имеющихся лечебных ресурсах российских курортов, но и о беспрецедентных ресурсах для активного, в частности, экстремального и приключенческого, туризма. К сожалению, зачастую информированность россиян о состоянии туристских ресурсов и туристских возможностей России замыкается Черноморским побережьем Кавказа, санаториями и базами 
отдыха в пределах территорий, областей проживания [1, с. 13].

Следует признать, что географическое положение России не позволяет ей в перспективе превратиться в регион массового туризма с целью традиционного летнего пляжного отдыха. Вместе с тем обширный культурно-исторический, природный потенциал России при грамотно построенном рыночном позиционировании позволит вывести внутренний и въездной туризм в число наиболее доходных составляющих туристской отрасли.

По итогам 2015 г. в рейтинге глобальной конкурентоспособности в сфере туризма Российская Федерация занимает 45-е место в общем зачёте среди 141 страны.

На рис. 1 представлен рейтинг отдельных факторов, определяющих конкурентоспособность для развития приключенческого туризма в РФ.

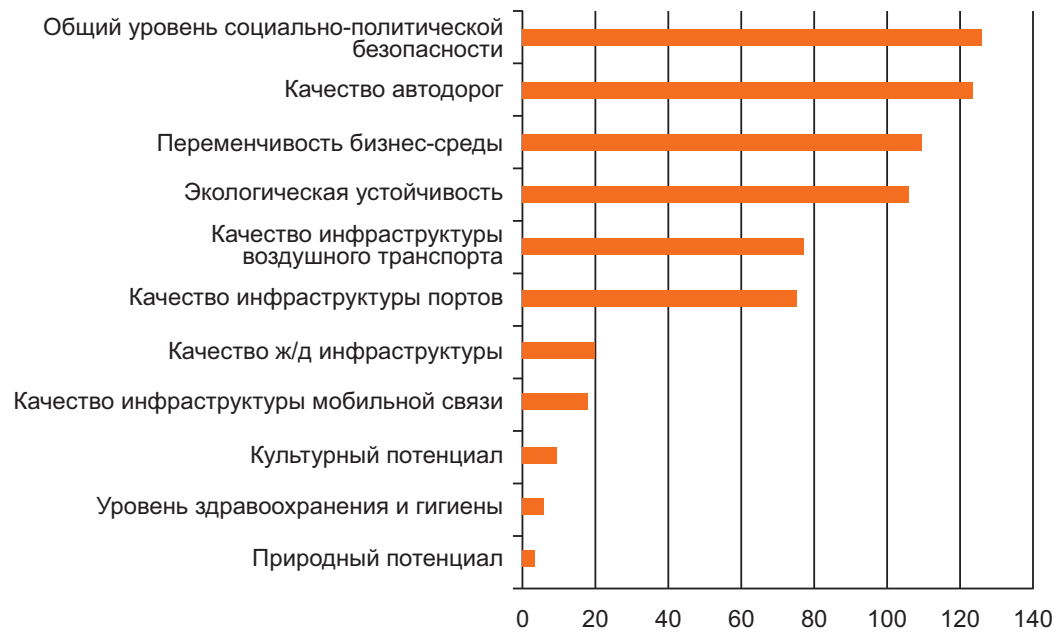

Рис. 1 - Факторы конкурентоспособности России для развития приключенческого туризма (место среди 141 страны по соответствующему фактору) $)^{5}$

Fig. 1 - Factors of Russia's competitiveness for the development of adventure tourism (place among 141 countries in the corresponding factor)

Такой рейтинг составляется раз в два года. Эта сильная позиция в определённой степени отражает тот факт, что большая часть данных была собрана до событий в Крыму, поэтому экономические последствия ситуации в области безопасности по-прежнему были незначительными.

Высокие баллы были присвоены России по природному потенциалу (4-место в рейтинге) и культурному (10-место). Сильными сторонами выделены инфраструктурные компоненты туризма: инфраструктура железнодорожного транспорта (20-е место) а также высокий уровень здравоохранения и гигиены (6-е место).

Проблемными сторонами названы невысокая безопасность, в том числе и политическая (126-е место), экологиче- ская устойчивость (106-е место) и переменчивость бизнес-среды (109-е место) ${ }^{6}$.

\section{Барьеры в развитии приключенческого туризма в РФ}

Приключенческий туризм уникален и тем, что очень органично объединяет практически все известные способы путешествий: альпинизм и скалолазание; дайвинг; рафтинг; спелеотуризм; путешествия

\footnotetext{
${ }^{5}$ Сост. по: Travel and Tourism Competitiveness Report 2015. URL: http://reports.weforum.org/ travel-and-tourism-competitiveness-report-2015/ index-results-the-travel-tourism-competitiveness-index-ranking-2015/ (дата обращения: 14.06.2017).

6 Index Results - The Travel \& Tourism Competitiveness Index Ranking 2015. URL: http://reports. weforum.org/travel-and-tourism-competitivenessreport-2015/index-results-the-travel-tourismcompetitiveness-index-ranking-2015/ (дата обращения: 14.06.2017).
} 
на воздушных шарах, дельтапланах и планерах; прыжки с парашютом; роупджампинг; пеший туризм; конные путешествия и мототуризм, а также многие другие разновидности [10].

Фактически для всех указанных видов активного приключенческого туризма имеются обширные возможности на территории России. По большей своей части природные регионы нашей страны обладают и могут предложить туристам труднодоступные памятники истории, археологии, этноса и культуры, которые представляют несомненный интерес для приключенческих туристов [9, с. 289].

Рыночный оборот приключенческого туризма нельзя назвать массовым явлением. Люди, испытывающие интерес и тягу к приключениям и даже экстриму, предпочитают организовывать тур самостоятельно, без привлечения туроператоров. Но все же в последнее время приключенческий туризм всё активнее находит поддержку у коммерческих структур. К путешествующим приходит понимание того, что приключение - это продукт и, как охота или рыбалка, может быть организовано и предложено профессионалами.

На настоящий момент развитие приключенческого туризма в России сдерживается целым рядом отрицательных факторов, к которым следует отнести:

- отсутствие комплексного взгляда на географию страны с позиций выделения приключенческих территорий;
- слабый ассортимент и невысокое качество предлагаемых сервисных услуг приключенческого туризма;

- неудовлетворительный уровень туристской инфраструктуры приключений, в частности, гостиниц среднего класса;

- отсутствие развитой и качественной сети современных транспортных магистралей [6];

- неудовлетворительная работа и низкое качество сервиса транспортных предприятий;

- распространение большого количества информации в средствах массовой информации о небезопасной социальной и криминогенной ситуации в России;

- неразвитость продвижения российских туристских приключенческих направлений за рубежом;

- слабая профессиональная подготовленность кадров индустрии туризма.

Заключение. Очевидно, что Россия должна использовать все имеющиеся ресурсы приключенческого туризма, следуя мировой тенденции смены спроса. В сложившихся условиях задача регулирующих государственных органов заключается в том, чтобы сделать его максимально востребованным и безопасным для участников, но при этом не допускать бесконтрольного потребления и уничтожения природных туристских ресурсов.

Имея конкурентоспособную туристическую приключенческую составляющую России удастся представить отечественным и зарубежным туристам яркий туристский продукт.

\section{Список источников:}

1. Баблиян С.А., Алиева Ф.Б. К вопросу о состоянии отрасли туризма в Российской Федерации // Курортно-рекреационный комплекс в системе регионального развития: инновационные подходы. 2014. №1. С. 12-14.

2. Богатырева Е.В. Приключенческий туризм // Туризм и отдых. 2006. №8. С. 23-25.

3. Бузни А.Н., Тренихина А.А. К вопросу об институциональной организации активного туризма // Научный альманах. 2016. №1-1(15). C. 48-53. DOI: 10.17117/na.2016.01.01.048.

4. Ильин В.Н., Федосова В.Ю. Проблемы и перспективы развития приключенческого туризма в России // Вестник алтайской науки: Журнал теоретических и прикладных исследований. 2009. №3(6). С. 193-195.

5. Казакова Е.А. Приключенческий туризм как одно из проявлений современных тенденций в рекреации // Актуальные проблемы физической культуры, спорта, туризма и рекреации. Сб. мат. V Всерос. с междунар. уч. науч.-практ. конф. студ. и асп. Казань: ПГАФКСиТ, 2017. С. 297-299.

6. Лукина Е.А. Основные причины роста популярности экстремального и приключенческого туризма // Современные проблемы сервиса и туризма. 2009. №1. С. 29-34. 
7. Ногина М.А. Приключенческий и экстремальный туризм: содержание понятий и причины популярности в молодёжной среде // Научно-методический электронный журнал «Концепт». 2015. №3. С. 126-130.

8. Романова И.В. Приключенческий туризм: эволюция и современное значение термина в зарубежных исследованиях мировой туристской индустрии // Вестник Воронежского государственного университета. Серия География и геоэкология. 2015. №4. С. 46-52.

9. Тилляева А.М., Давыдова О.В. Приключенческий туризм в России: состояние и перспективы развития // В сб.: Стратегия развития индустрии гостеприимства и туризма: VI Междунар. Интернет-конф. Орёл: ОГУ, 2016. С. 288-291.

10. Тренихина А.А. К вопросу об активном туризме // Вестник современных исследований. 2017. №1-2(4). С. 157-171.

11. Тренихина А.А. Сущностная характеристика понятия и основных категорий активного туризма // Велес. 2016. №1-3(31). С.51-54.

12. Цветков Е.И. Проблемы и перспективы терминологии спортивно-приключенческого туризма // Индустрия туризма: возможности, приоритеты, проблемы и перспективы. 2015. №8-1. С. 131147.

13. Dickson T., Dolnicar S. No risk, no fun: The role of perceived risk in adventure tourism. CD Proceedings of the 13th International Research Conference of the Council of Australian University Tourism and Hospitality Education (CAUTHE 2004). Wollongong, 2004.

14. Fynn P. Adventure Tourism: The New Frontier // International Journal of Contemporary Hospitality Management. 2004. Vol.16. Iss.2. Pp. 144-144. DOI: 10.1108/09596110410520043.

15. Schneider P.P., Vogt C.A. Applying the 3M Model of Personality and Motivation to Adventure Travelers // Journal of Travel Research. 2012. Vol.51. Iss. 6. Pp. 704-716. DOI: 10.1177/0047287512451134.

16. Williams P., Soutar G., Ashill N., Naumann E. Value drivers and adventure tourism: A comparative analysis of Japanese and Western consumers // Journal of Service Theory and Practice. 2015. Vol.27. Iss.1. Pp. 102-122. DOI: 10.1108/JSTP-05-2015-0116.

\author{
Tatiana V. NIKONOVA a, Valeriya Yu. GUSAROVA ' , Olga N. PEREZHOGINA c \\ a-c Volga Region State Academy of Physical Culture, Sports and Tourism \\ (Kazan, Rep. of Tatarstan, Russia); \\ a PhD in Economics, Associate Professor; e-mail: viktta@mail.ru; \\ b,c PhD in Economics, Senior Lecturer; ${ }^{b}$ e-mail: vgusarova@mail.ru; ${ }^{c}$ \\ e-mail: perezhogina-on@yandex.ru
}

\title{
FEATURES OF ADVENTURE TOURISM AND PROSPECTS FOR ITS DEVELOPMENT IN RUSSIA
}

\footnotetext{
In the last few years, the development of adventure tourism as a kind of active tourism initiatives, tourism firms have become more visible. Adventuretourism (adventure tourism) is different in originality and unusual variety of tours. It includes exotic travel, extreme sports, a specific move connected with risk and danger to life. In this regard, the article highlights the criterion of the differences of adventure tourism from other types of active travel. The authors point out the the main reasons for the popularity of adventure tourism of the article, among which are following: healthy lifestyle popularization, prestige of the activity of the pleasure, the desire of the modern tourist for new experiences and the rush of emotion, the possibility of self-realization, improving credibility and promotion in society through adventure tourism, including with help of social networks. Taking into account the growing popularity of adventure tourism in the world, the authors of the article analyzes the factors of Russia's competitiveness for the adventure tourism development. It is revealed that strengths are rail transport infrastructure and a high level of health and hygiene. The article admits that now the development of adventure tourism in Russia is constrained by a number of negative factors to be overcome. Among them are the lack of a comprehensive look at the geography of Russia from the standpoint of the selection of adventure territories, the unsatisfactory level of tourist infrastructure of adventure, poor range and low quality of services adventure tourism, weak professional background of the staff.

Keywords: adventure tourism, active tourism, tourist infrastructure, global competitiveness o*rating, adventure tourism services.
} 


\section{References}

1. Bablijan, S. A., \& Alieva, F. B. (2014). K voprosu o sostojanii otrasli turizma v Rossijskoj federacii [On the state of the tourism industry in the Russian Federation]. Kurortno-rekreacionnyj kompleks v sisteme regional'nogo razvitija: innovacionnye podhody [Resort and recreation complex in the system of regional development: Innovative approaches], 1, 12-14. (In Russ.).

2. Bogatyreva, E. V. (2006). Prikljuchencheskij turizm [Adventure tourism]. Turizm i otdyh [Tourism and Vacation], 8, 23-25. (In Russ.).

3. Buzni, A. N., \& Trenikhina, A. A. (2016). K voprosu ob institucional'noj organizacii aktivnogo turizma [On the institutional organization of active tourism]. Nauchnyj almanah [Science Almanac], 15, 48-53. (In Russ.).

4. Iljin, V. N., \& Fedosova, V. Yu. (2009). Problemy i perspektivy razvitija prikljuchencheskogo turizma v Rossii [Issues and perspectives for the development of adventure tourism in Russia]. Vestnik altajskoj nauki: Zhurnal teoreticheskih i prikladnyh issledovanij [Bulletin of the Altai Science: Journal of Theoretical and Applied Research], 3(6), 193-195. (In Russ.).

5. Kazakova, E. A. (2017). Prikljuchencheskij turizm kak odno iz projavlenij sovremennyh tendencij v rekreacii [Adventure tourism as one of the manifestations of modern trends in recreation]. Aktual'nye problemy fizicheskoj kul'tury, sporta, turizma i rekreacii [Actual problems of physical culture, sports, tourism and recreation]: The V All-Russia scientific-practical conference of students and graduate students with international participation. Kazan: PGAFKSIT, 297-299. (In Russ.).

6. Lukina, E. A. (2009). Osnovnye prichiny rosta populjarnosti ekstremal'nogo i prikljuchencheskogo turizma [Key Reasons for Rising Popularity of Extreme and Adventure Tourism]. Sovremennye problemy servisa i turizma [Service and Tourism: Current Challenges], 1, 29-34. (In Russ.).

7. Nogina, M. A. (2015). Prikljuchencheskij i ekstremal'nyj turizm: soderzhanie ponjatij i prichiny populjarnosti v molodezhnoj srede [The content of concepts and reason of popularity in the youth environment: adventure and extreme tourism]. Nauchno-metodicheskij elektronnyj zhurnal "Koncept" [Periodic scientific and methodological ejournal "Koncept"], 3, 126-130. (In Russ.).

8. Romanova, I. V. (2015). Prikljuchencheskij turizm: evoljucija i sovremennoe znachenie termina v zarubezhnyh issledovanijah mirovoj turistskoj industrii [Adventure tourism: evolution and contemporary meaning of the termin the framework of world tourist industry foreign studies]. Vestnik Voronezhskogo gosudarstvennogo universiteta. Serija Geografija i geojekologija [Proceedings of Voronezh State University. Series: Geography. Geoecology], 4, 46-52. (In Russ.).

9. Tilljaeva, A. M., \& Davydova, O. V. (2016). Prikljuchencheskij turizm v Rossii: sostojanie i perspektivy razvitija [Adventure tourism in Russia: The state and development prospects]. Strategija razvitija industrii gostepriimstva i turizma [Strategy for the development of hospitality and tourism industry]: The VI International Internet Conference. Orel: OSU, 288-291. (In Russ.).

10. Trenikhina, A. A. (2017). K voprosu ob aktivnom turizme [Active tourism revisited]. Vestnik sovremennyh issledovanij [Bulletin of Modern Studies]. 1-2(4), 157-171. (In Russ.).

11. Trenikhina, A. A. (2016). Sushhnostnaja harakteristika ponjatija i osnovnyh kategorij aktivnogo turizma [Essential characteristics of concept and basic categories of active tourism]. Veles, 1-3(31), 51-54. (In Russ.).

12. Cvetkov, E. I. (2015). Problemy i perspektivy terminologii sportivno-prikljuchencheskogo turizma [Problems and prospects of the terminology of sports and adventure tourism]. Industrija turizma: vozmozhnosti, prioritety, problemy i perspektivy [Tourism industry: opportunities, priorities, challenges and prospects], 8(1), 131-147.

13. Dickson, T., \& Dolnicar, S. (2004). No risk, no fun: The role of perceived risk in adventure tourism. CD Proceedings of the 13th International Research Conference of the Council of Australian University Tourism and Hospitality Education (CAUTHE 2004). Wollongong.

14. Fynn, P. (2004). Adventure Tourism: The New Frontier. International Journal of Contemporary Hospitality Management, 16(2), 144-144. doi: 10.1108/09596110410520043.

15. Schneider, P. P., \& Vogt, C. A. (2012). Applying the $3 \mathrm{M}$ Model of Personality and Motivation to Adventure Travelers. Journal of Travel Research, 51(6), 704-716. doi: 10.1177/0047287512451134.

16. Williams, P., Soutar, G., Ashill, N., \& Naumann, E. (2015). Value drivers and adventure tourism: A comparative analysis of Japanese and Western consumers. Journal of Service Theory and Practice, 27(1), 102-122. doi: 10.1108/ JSTP-05-2015-0116.

\footnotetext{
Никонова Т.В., Гусарова В.Ю., Пережогина О.Н. Особенности приключенческого туризма и перспективы его развития в России // Современные проблемы сервиса и туризма. 2017. T.11. №3. C. 51-58. DOI: 10.22412/1995-0411-2017-113-51-58.
}

Дата поступления статьи: 19 июня 2017 г.
Nikonova, T. V., Gusarova, V. Yu., \& Perezhogina, O. N. (2017). Features of adventure tourism and prospects for its development in Russia. Sovremennye problemy servisa i turizma [Service and Tourism: Current Challenges], 11(3), 51-58. doi: 10.22412/1995-0411-2017-11-3-51-58. (In Russ.).

Received June 19, 2017 